\title{
Editorial: A new journal in radiology
}

\author{
Robert Hermans • Adrian K. Dixon
}

Received: 18 November 2009/Accepted: 19 November 2009/Published online: 16 January 2010

(C) European Society of Radiology 2009

It is a great pleasure to write the first editorial of a new journal! This marks a significant step in the development of the publications emanating from the European Society of Radiology. After 20 years the success of European Radiology now seems very well established. This is a huge triumph for, firstly, the late Professor Joseph Lissner (Founding Editor) and then the remarkable endeavours of Professor Albert Baert (Honorary Editor). To see a journal start form scratch and rapidly become one of the leading general radiology journals in the world in the space of 20 years is a remarkable feat. We all hope that Insights into Imaging will have a similar meteoric career.

The need for such a journal is reflected by a very high rejection rate of articles from European Radiology, particularly pictorial reviews and those concerned with policy, as well as guidelines and lengthy recommendations from the European subspecialty groups. Thus, this new journal will assimilate all these needs and, in some ways, may prove more popular with the average European general radiologist than the more scientific output found in European Radiology. Indeed, parallels elsewhere in the world suggest that pictorial reviews and "how to do it" articles are more widely read, even if less widely cited, than many basic science articles.

The new journal also allows the permanent recording of various policy statements emanating from the ESR. In the past many working groups/working parties have produced excellent paper documents, some of which have been of the very highest importance. But without an electronic database

R. Hermans $\cdot$ A. K. Dixon $(\bowtie)$

Insights into Imaging $\left(\mathrm{I}^{3}\right)$, Editorial Office,

Neutorgasse 9/2,

AT-1010 Vienna, Austria

e-mail: editor@i3-journal.org and home, they are difficult to find, and it is also almost impossible for future researchers to quote them. Hence the need for a vehicle to embrace all such policy documents, which will usually be quoted as an ESR official document, merely listing the members of the working party (even if they have done most of the writing and all of the hard work!). The ESR office in Vienna will handle the new journal, and new members of staff have been taken on to facilitate this. An agreement has been reached for the initial phase with Springer Verlag, and we are confident that their professional expertise will mean that this journal is, like European Radiology, of the highest quality. It will be overseen by the ESR publications committee, and the first Editor has now been selected (Professor Robert Hermans, Leuven, Belgium). He will work closely with the Chair of the publications committee (Professor Adrian Dixon, Cambridge, UK) in what is seen to be a major development for the ESR. Several esteemed colleagues have been invited to join the Editorial Board, which will be further expanded in the future to represent the wide variety of interests alive among the members of ESR.

So please take note of this new publication, and send in your educational reviews and articles on best practice in radiology, policy or controversies to this new venture. It is only by your support that it will become a success and compete with other similar journals in the future. However, with the full readership within the ESR now standing at over 45,000 members, we feel confident that the radiology community will welcome this new approach and support it to the hilt.

Robert Hermans, Incoming Editor, Insights into Imaging Adrian K. Dixon, Chairman of the ESR Publications Committee

November 2009 